\title{
Experimental and Quantum Chemical Studies on the Corrosion Inhibition of Mild Steel By 2-((Thiophen-2-Ylmethylene) Amino)Benzenethio in $1 \mathrm{M} \mathrm{HCl}$
}

\author{
Iman Mahdi Mohammed
}

Received 2/5/2018, Accepted 11/11/2018, Published 11/3/2019

This work is licensed under a Creative Commons Attribution 4.0 International License.

\begin{abstract}
:
The impact of a Schiff base namely 2-((thiophen-2-ylmethylene)amino)benzenethiol to corrode mild steel in $1 \mathrm{M} \mathrm{HCl}$ resolved was evaluated using different weight loss technique and scanning electron microscopy (SEM).different weight measurements to expand that the 2-((thiophen-2-ylmethylene) amino) benzenethiol inhibits the corrosion of mild steel through adsorbing of top for mild steel and block the active locality. The inhibitive impacts of 2-((thiophen-2-ylmethylene)amino)benzenethiol increase with increasing concentration and decrease with increasing temperature. SEM to checking revealed that the alloy surface was quite unaffected and formed protective film on its surface. The investigated inhibitor become as a shield for the mild steel surface from corrosive solution. Quantum chemical investigations corroborate experimental results well. The synthesized inhibitor was characterized employing NMR (nuclear magnetic resonance), FT-IR (Fourier-transform infrared) spectroscopies and CHN elemental analysis.
\end{abstract}

Key words: Corrosion steel, Inhibiter, Thiophene-2-carbaldehyde.

\section{Introduction:}

Mild steel is the most widely employ alloy in industries such as gas and oil (1). Corrosion of alloys are of considerable economically relevance and destroy many industries and their applications $(2,3)$. The protection of alloys from corrosion caused by environment, aggressive electrolytes (4) using organic molecules might permeate the layer or contact the surface of alloy directly after failure of coating under stress such as stone chipping of automotive coatings (5). Corrosive media have been utilized in the activities of industries naming acid pickling, descaling and cleaning. Employing of natural organic inhibitors become the most active and cost successful process of reduce alloys corrosion (6-8). Synthetic organic molecules that have heteroatoms (such as nitrogen, sulfur or oxygen) in addition to pielectron systems were approved to exhibit excellent inhibition efficiencies (9-11). The inhibition impact such organic molecules depend on capability to adsorb on alloy surface. The inhibition impact of the synthesized organic molecules are commonly revolve on the replacement of $\mathrm{H}_{2} \mathrm{O}$ molecules by organic inhibitor and form protective film on the alloy surface (12).

Department of Chemistry, College of Science for Woman, University of Baghdad, Baghdad, Iraq.

E-mail: emmm-Abd@yahoo.com
In this study, new Schiff base molecule namely 2-((thiophen-2-ylmethylene) amino) benzenethiol has been synthesized, characterized and evaluated for it inhibition impacts towards mild steel corrosion reaction in corrosive solution of hydrochloric acid employing different weight and scanning electron microscope technicality. Aquality, chemical activities and structure relationship of the corrosion inhibition were also investigated.

\section{Martials and Methods}

Synthesis of corrosion inhibitor, 2((thiophen-2-ylmethylene) amino) benzenethiol All the dissolvent solution and priority materials have been acquired in "Sigma-Aldrich Malaysia". FT-IR "Fourier-transform infrared spectroscopy" spectrum for the corrosion inhibitor has been recorded through "Shimadzu 8300 spectrometer". A Carbon, Hydrogen \& Nitrogen Analyzer could be utilized for CHN analysis via Carlo Erba 5500 CHN elemental analysis". The spectrum of NMR "Nuclear magnetic resonance spectroscopy" was recorded through Bruker Spectro-spin instrument with $300 \mathrm{MHz}$ UltraShield using the solvent Hexadeuterodimethyl sulfoxide and Tetramethylsilane "TMS" as internal standard for calibrating chemical shift. The preperation of 2((thiophen-2-ylmethylene) amino) benzenethiol has been done as in Fig. 1, by the mixed of an equimolar of 2-aminobenzenethol, thiophene-2- 
carbaldehyde in ethanol as a solvent than reflux. After $5 \mathrm{~h}$., filtered and recrystallized from ethanol than dried to produce yellow precipitate with the yield of 66\%. M.P.=180-182.

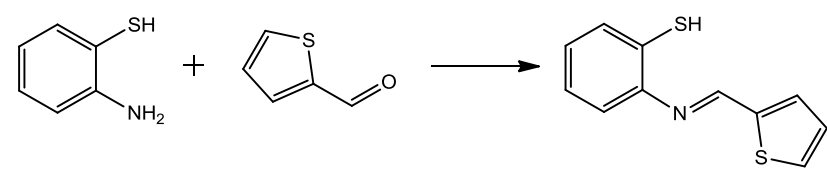

Figure 1. The synthesis of the corrosion inhibitor.

\section{Corrosion tests}

Mild steel coupons texture of C $(0.21 \%)$, Si $(0.38 \%), \mathrm{Mn}(0.05 \%), \mathrm{P}(0.09 \%), \mathrm{Al}(0.01 \%)$, and $\mathrm{Fe}(99.21 \%)$ were utilized for weight loss investigations. The coupons were cleaned according to the standard procedure to be specific ASTM G1-03 (13-22). In a typical methodology, coupons were suspended volume $200 \mathrm{~mL}$ of a corrosive solution (in duplicate) to try or not of 2((thiophen-2-ylmethylene) amino) benzenethiol. Various concentrations of 2-((thiophen-2ylmethylene) amino)benzenethiol $(0.1,0.2,0.3$, 0.4 and $0.5 \mathrm{mM}$ ) in $1 \mathrm{M} \mathrm{HCl}$ as corrosive solution were utilized at $303,313,323$ and $333 \mathrm{~K}$. After $5 \mathrm{~h}$ as reaction time the mild steel to check coupons then to rinse with distilled water, ethanol and to drain then weighted intire.

The inhibition competence were calculated by Equation 1(23).

$$
I E \%=\frac{W_{o}-W_{1}}{W_{o}} \times 100
$$

"where $\mathrm{w}_{\mathrm{o}}$ is the weight loss in absence of the tested inhibitor and $\mathrm{w}_{1}$ is the weight loss in presence of the tested inhibitor".

Corrosion quickness calculated by the Equation 2(24).

$$
C_{R}=\frac{m g}{c m^{2} h^{1}}
$$

\section{Mild Steel Surface Characterization}

Mild steel coupons surfaces were investigated by scanning electron microscope (SEM) that immersed in $\mathrm{HCl}$ solution before and after added of the corrosion inhibitor at the concentration $0.5 \mathrm{mM}$ for $5 \mathrm{~h}$ at $303 \mathrm{~K}$

\section{Computation Methods}

Density function theorem (DFT) was employed to elucidate optimization texture tested inhibitor and quantum parameters "EHOMO and ELUMO (Energy of highest occupied molecular orbital and Energy of lowest unoccupied molecular orbital), dipole moment $/ \mu$, chemical hardness $/ \eta$, chemical softness $/ \sigma$ and
Electrophilicity index/ $\omega^{\prime \prime}$ at the function DFTB3LYP with the basis set 6-31G. The mechanism of inhibiton of the investigated inhibitor depending on quantum parameters were figured as in Equations 3-7 (14).

$$
\begin{array}{ll}
\Delta E=E_{\text {LUMO }}-E_{\text {HомO }} & 3 \\
\eta & =\frac{1}{2}\left(E_{\text {HOMO }}-E_{\text {LUMO }}\right) \\
\sigma & =\frac{1}{\eta} \\
\mu & =\frac{1}{2}\left(E_{\text {HOMO }}+E_{\text {LUMO }}\right) \\
\omega & =\frac{\mu^{2}}{2 \eta}
\end{array}
$$

\section{Results and Discussion \\ Structure}

The inhibitor 2-((thiophen-2-ylmethylene) amino)benzenethiol was facilely prepared in superior yield through the reaction of 2aminobenzenethol and thiophene-2-carbaldehyde under reflux conditions. Molecular weight of 2((thiophen-2-ylmethylene)amino)benzenethiol was 219 regarding to chemical formula C11H9NS2 that was confirmed by elemental analysis. Elemental analysis (C.H.N): C, 60.24 (59.82); H, 4.14 (4.48) and $\mathrm{N}, \quad 6.39(7.01)$. Fourier-transform infrared spectroscopy (FTIR) is a method applied infrared spectra in order to characterized the chemical formula of the tested compound. This technique was employee to investigated the functional groups of the synthesized inhibitor to elucidated and confirmed it structure. No amino or carbonyl absorption bands were observed for 2-((thiophen-2ylmethylene)amino)benzenethiol in FTIR spectrum.

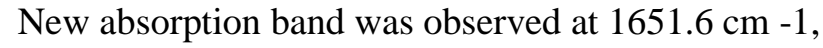
for the azomethine group. Another absorption bands were observed at thiol group at $2363.73 \mathrm{~cm}-1$; carbon-sulfur bond has asym and sym absorption bands at 1053.68 and $744.94 \mathrm{~cm}-1$ respectively. Nuclear magnetic resonance spectroscopy, usually recognized as1H- NMR spectroscopy or MRS "magnetic resonance spectroscopy", is a spectroscopic method to realize, the magnetic fields around nuclei.1H- NMR is the firm technique to elucidate organic molecules. The general kind of 1H- NMR were H-1and13 C- NMR spectroscopy. The 1H- NMR spectrum showed singlets at $\delta 3.39$ ppm, due to the $\mathrm{SH}$ proton and multplate was observed at $\delta 7.03-7.81 \mathrm{ppm}$ due to the aromatic and azomethine protons.

\section{Corrosion measurements}

Weight loss measurements have been done in coupons top of mild steel in $1 \mathrm{M} \mathrm{HCl}$ in absence and presence of 2-((thiophen-2-ylmethylene) amino)benzenethiol for reaction time 5h. Fig.2 
represents the inhibition efficiencies for various concentrations for added compound 2-((thiophen2-ylmethylene)amino)benzenethiol at 303, 313, 323 and $333 \mathrm{~K}$, respectively.

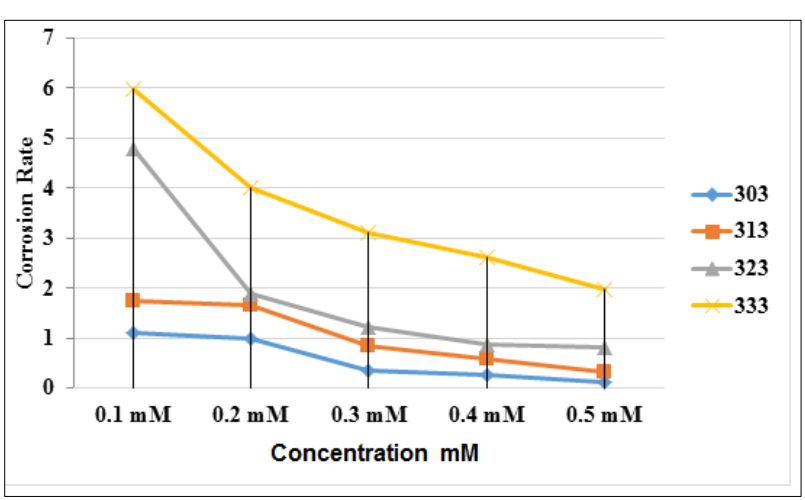

Figure.2 Inhibitor concentration effect on corrosion rate at 303-333K.

Figure 2, explain the relation $\mathrm{CR}$ with different focusing of inhibitor at versus temperature degrees. The $\mathrm{CR}$ reduce regarding to increasing of inhibitor concentration in corrosive resolved. CR decrease to swear together with concentration increasing at the $313 \mathrm{~K}$ to reach $0.32 \mathrm{mg} \cdot \mathrm{cm}-2 \cdot \mathrm{h}-1$ at $0.5 \mathrm{mM}$ as inhibitor concentration. As in Figure 2, the curves at $323 \mathrm{~K}$ and 333 analogous forms in the curves at $303 \mathrm{~K}$ and $313 \mathrm{~K}$.

Figure 3 displayed the locality of the IE\% to reflect the impact of various concentrations started from 0.1 to $0.5 \mathrm{mM}$ with different degrees of temperature $\mid 303,313,323$ and $333 \mathrm{~K} "$. It is obvious that the IE\% was not enough influenced by studied temperature degrees to begin from $303 \mathrm{~K}$ to 313 , exceptionally of concentrations $0.2-0.4 \mathrm{mM}$; whilst at the highest investigated concentration the inhibition quite increased. At the highest studied temperature degree, it can be seen that the inhibitor concentration has not considerable effects IE\% and this result might be due to waste of the scholar ship inhibitor.

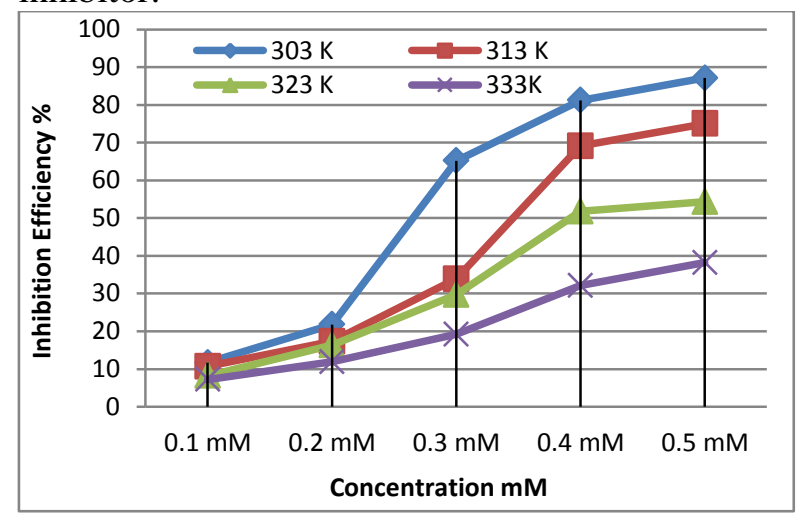

Figure 3. Effects different kinds concentrations of 2-((thiophen-2-ylmethylene) amino) benzenethiol on inhibition performance at different temperature degrees
Evaluation of the product demonstrated IE in target corrosion inhibitor increased to make parallel concentration increased. Most active value of IE was $87.1 \%$ that at the highest studied concentration for 2-((thiophen-2-ylmethylene) amino) benzenethiol. Also, the ideal concentration for 2-((thiophen-2-ylmethylene)amino)benzenethiol was $0.5 \mathrm{mM}$, this was due to no considerable changes in IE at more than this concentration. The Arrhenius equation (as in equation 8) was employed to displayed the temperature impacts on the IE of 2((thiophen-2-ylmethylene)amino)benzenethiol as investigated inhibitor compound $(25,26)$.

$$
\begin{aligned}
& \ln C_{R}-E_{a}(\text { activation energy }) \\
& =\frac{-}{R(\text { gas constant }) T \text { (temperature })} \\
& +\ln A \text { (Arrhenius factor })
\end{aligned}
$$

The energy in absence and presence of 2((thiophen-2-ylmethylene)amino)benzenethiol have been calculated depending on equation 9 and Arrhenius plots which demonstrated in fig. 4 .

$$
\text { Slope }=-\frac{\Delta E_{a}}{2.303 R(\text { gas constant })}
$$

The Ea value was $88.4 \mathrm{kJmol}-1$ for 2((thiophen-2-ylmethylene) amino) benzenethiol. This refer to importance of presence of 2((thiophen-2-ylmethylene) amino) benzenethiol in corrosive solution which can be compare with Ea value in absence of 2-((thiophen-2-ylmethylene) amino) benzenethiol and hence this result indicate that 2-((thiophen-2-ylmethylene) amino) benzenethiol molecules forming barrier as protection film on the top of mild steel (25).

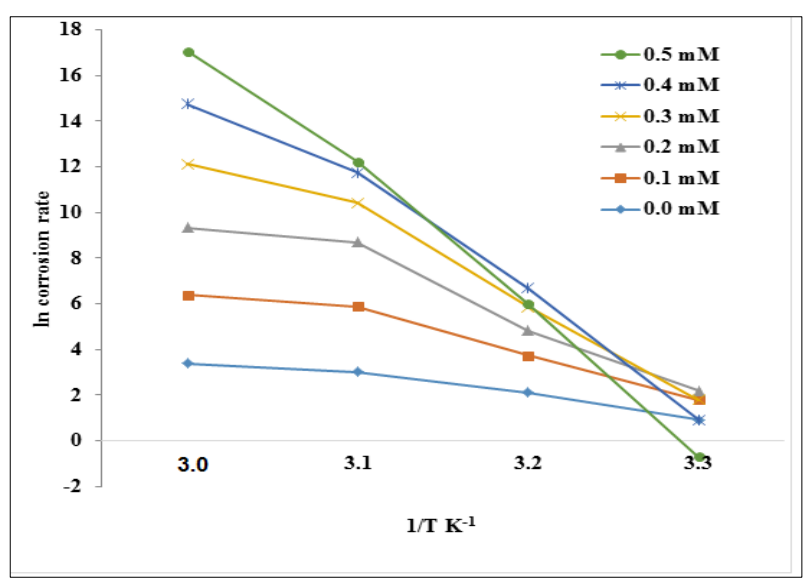

Figure 4.The effects of degrees of temperature on the CR "corrosion rate" based on Arrhenius plot of for mild steel in corrosive solution.

\subsection{Surface Morphology Investigations}

From Fig 5, it can be shown that the SEM images of the of MS top samples which to dip in corrosive resolvent for five hours, when absence (Figure 5a) and presence (Fig. 5b) of 2-((thiophen- 
2-ylmethylene) amino) benzenethiol as corrosion inhibitor stabilized destruction in MS surface (Fig. 5 a) of samples. As well, the SEM image for samples which immersed in corrosive solution for five hours, in presence of corrosion inhibitor 2((thiophen-2-ylmethylene) amino) benzenethiol at concentration of $0.5 \mathrm{mM}$ was smooth and coated by protective film. This indicate that the inhibitor 2((thiophen-2-ylmethylene) amino) benzenethiol adsorbed and block the surface of MS from acidic impact.

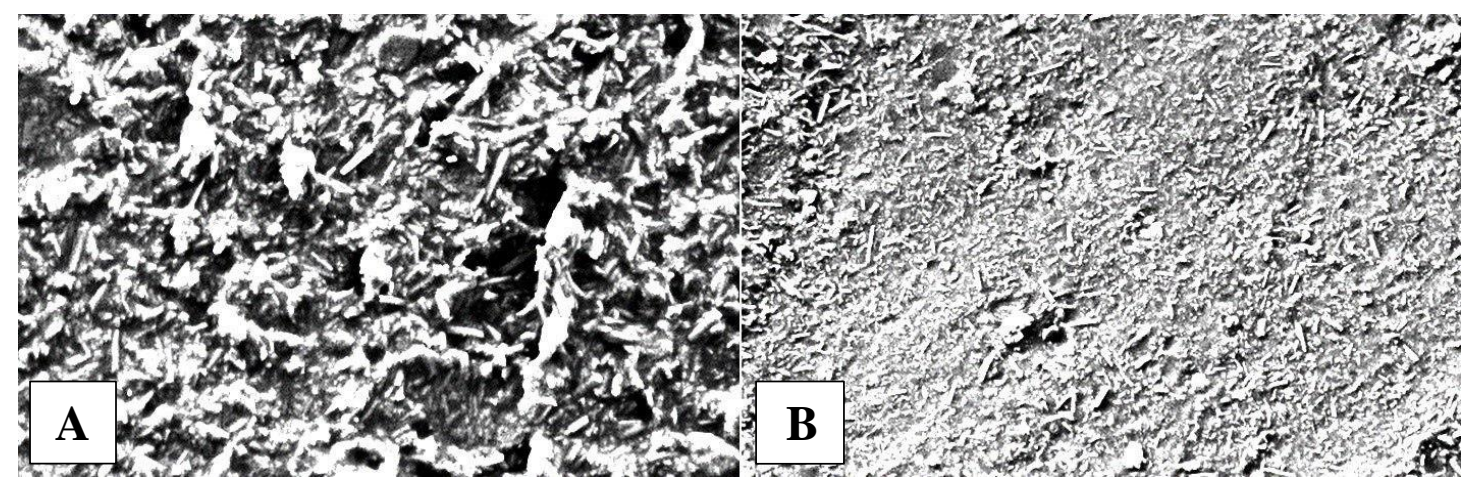

Figure 5. The SEM pictures of samples of MS surface in corrosive acid in the absence (a) and presence (b) of inhibitor.

\section{Quantum Calculations}

The inhibitor 2-((thiophen-2-ylmethylene) amino) benzenethiol has different chemical compounds by having nitrogen and sulfur atoms in addition to aazomethan group with resonance impact, through the linkage between thiophene groups, azomethine and phenyl group jointly yield compound with unique characteristics due to resonance and inductive impress. It is obvious from ideal texture for 2-((thiophen-2-ylmethylene) amino) benzenethiol, the geometrical structure is planar because of the cycliozation of the molecule. Electronic texture for 2-((thiophen-2ylmethylene) amino) benzenethiol was considered utilizing of DFT-B3LYP/6-311G. HOMO "highest occupied molecular orbital" and LUMO "lowest unoccupied molecular orbital" to check for 2-((thiophen-2-ylmethylene) amino) benzenethiol and to present as in Figure 6 . Parameters such as $\Delta \mathrm{E}$ "energy gap $=$ ELUMO - EHOMO", $\mu$ "dipole moment" and $\chi$ "electronegativity" have been demonstrated as in Table 1. EHOMO displayed electron capability of 2-((thiophen-2-ylmethylene)amino)benzenethiol with electron susceptibility as comparing to other investigated inhibitors(27-32). The releasing electronic group namely thiophene linkage to phenyl group via azomethane in 2-((thiophen-2ylmethylene)amino)benzenethiol increase the electron donating capabilities of 2-((thiophen-2ylmethylene)amino)benzenethiol molecules as in
Fig. 6. EHOMO and ELUMO could be considered as the affinity of 2-((thiophen-2-ylmethylene) amino) benzenethiol molecules. $\Delta \mathrm{E}$ is major parameter which depict the linkage of MS surface and inhibitor molecules. The investigated inhibitor 2-((thiophen-2-ylmethylene) amino) benzenethiol have different of energy hole and that of $3.898 \mathrm{eV}$ as displayed in Fig. 6 and table 1. Generally, investigated compound with minimum $\chi$ refer to higher electron propensity showed higher inhibition efficiency. In this search, $\chi$ completely to lean to close results. The dipole moment for the inhibitor that the dipole moment with high value indicating to excellent corrosion inhibitor. Regarding to this investigation, the value dipole moment of 2-((thiophen-2-ylmethylene) amino) benzenethiol was 4.599 that indicate to 2((thiophen-2-ylmethylene) amino) benzenethiol molecules have excellent achievement inhibition activity. From table 1 we can say that $\mu$ of 2 ((thiophen-2-ylmethylene) amino) benzenethiol molecules have higher value comparing to $\mu$ of water molecules and this refer to that of 2((thiophen-2-ylmethylene)amino)benzenethiol molecules have higher activities to react either physically or chemically with the MS surface. From this it can be conclude that, 2-((thiophen-2ylmethylene) amino) benzenethiol molecules may be taking up on the MS surface through removing of water molecules(33-35). 


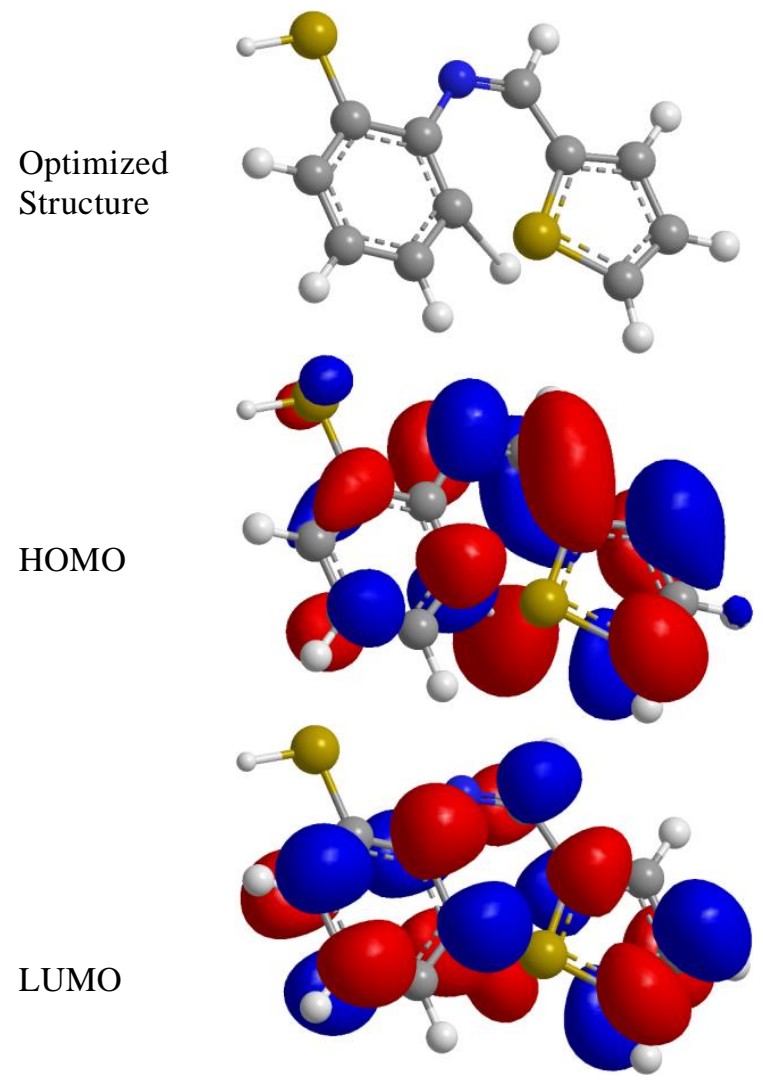

Figure 6. Electronic structures of 2-((thiophen2-ylmethylene)amino)benzenethiol molecule

Table 1. Electronic factors for 2-((thiophen-2ylmethylene)amino)benzenethiol molecule

\begin{tabular}{ll}
\hline Factors & Inhibitor \\
\hline HOMO [eV] & -4.832 \\
LUMO [eV] & -0.934 \\
$\Delta \mathrm{E}=$ ELUMO - EHOMO [eV] & 3.898 \\
Dipole moment $\mu$ & 4.599 \\
Electron affinity $X$ & 4.832 \\
Ionization potential $(\mathrm{I})$ & 0.934 \\
Electronegativity $\chi\left[\chi=\frac{I+A}{2}\right]$ & 2.883 \\
Global hardness $\left[\eta=\frac{I-A}{2}\right]$ & 1.949 \\
Chemical softness $\left[S=\frac{1}{\eta}\right]$ & 0.513 \\
\hline
\end{tabular}

The factors hardness and softness were employee to assess the reactivity with stability for the studied molecules. Hardness demonstrate the resistance towards the electron polarization of molecules. To harden molecules have big energy gap and soft molecules have fine energy gap (31). In this work, the 2-((thiophen-2-ylmethylene) amino)benzenethiol molecules to harden value 1.949 , they were proved that 2-((thiophen-2ylmethylene)amino)benzenethiol molecules that to harden with small value was possible to be as well inhibitor. To post of electron in easy way need maximum value chemical softness (32). 2((thiophen-2-ylmethylene) amino) benzenethiol molecules have chemical softness equel to
$0.5131 \mathrm{eV}$ so, it has the maximum inhibition achievement.

\section{Conclusion:}

The effect of inhibition of the inhibitor 2((thiophen-2-ylmethylene) amino) benzenethiol on MS surface in corrosive solution has been investigated employing different weight and SEM "scanning electron microscopy" device. Quality chemistry has been employee to prove trial results. The different weight findings displayed 2((thiophen-2-ylmethylene)amino)benzenethiol inhibit the corrosive solution and the inhibition performance increase regarding to increasing of concentration. The inhibition activity was $87.1 \%$ which displayed the high protection activity against hydrochloric acid. The molecules of 2((thiophen-2-ylmethylene) amino) benzenethiol inhibit the corrosion at MS in $1 \mathrm{M}$ hydrochloric acid through adsorbing on the top of MS and form protection film by physisorption or chemisorption SEM pictures to indicat that 2-((thiophen-2ylmethylene) amino) benzenethiol adsorbed on MS the top and shield the MS surface from corrosive solution. Quantum chemistry displayed that active sites in the molecules of 2-((thiophen2-ylmethylene) amino) benzenethiol have sulphur and nitrogen atoms with pi-electron.

\section{Acknowledgment}

The authors gratefully to thank the Chemistry Department, Women college of Science, University of Baghdad.

\section{Conflicts of Interest: None.}

\section{References}

1. Reston VA. Mineral commodity summaries 2016. US Geological Survey,doi; 2016; 1-205.

2. Choi SG .An estimation of corrosion costs in primary metals industry in Korea: Input-output approach. J Econ.Stu. 2014;32: 53-74.

3. Kim YS, Lim H K, Kim JJ, Hwang WS, Park YS. Corrosion cost and corrosion map of Korea. Corros. Sci. and Techno. 2011;10: 3368-3383 .

4. Dias P, Carneiro C, Andrade L, Sousa J, Machado J , Mendes A. Characterization of a water-based paint for corrosion protection. J. Coat. Technol. Res. 2012; 9(3): 365-374.

5. Verma C, Olasunkanmi LO, Ebenso EE, Qurraisi M, Obot I. Adsorption behavior of glucosamine-baseed, pyrimidine-fused heterocyles as green corrosion inhibitors for mild steel:experimental and theoretical studies.J Phys Chem C .2016 ;120:11598-611.

6. Breston JN. Corrosion control with organic inhibitors. Ind. Eng. Chem.1952; 44: 1755-1761.

7. Olasunkanmi, LO, Obot IB, Kabanda M M, Ebenso EE. Some quinoxalin-6-yl derivatives as corrosion 
inhibitors for mild steel in hydrochloric acid: experimental and theoretical studies. J. Phys. Chem. 2015;C 119:16004-16019.

8. Baskar R, Gopiraman M, Kesavan D, Kim IS, Subramanian K. Synthesis, characterization, and electrochemical studies of novel biphenyl based compounds. Ind. Eng. Chem. Res.2012; 51: 39663974.

9. Schmitt G. Application of inhibitors for acid media: report prepared for the European federation of corrosion working party on inhibitors. Br. Corros. J . 1984;19: 165-176.

10. Asegbeloyin JN, Ejikeme, PM, Olasunkanmi LO, Adekunle AS, Ebenso E E. A novel Schiff base of 3acetyl-4-hydroxy-6-methyl-(2H)pyran-2-one and 2,2'(ethylenedioxy)diethylamine as potential corrosion inhibitor for mild steel in acidic medium. Materials. 2015; 8: 2918-2934.

11. Saranya J, Sounthari P, Parameswari K, Chitra S. Acenaphtho[1,2-b]quinoxaline and acetaphtho[1, 2b]pyrazine as corrosion inhibtors formild steel in acid medium,Measurement . 2016;77:175-86.

12. Yuce AO, Mert BD, Kardas G, Yazici B. Electrochemical and quantum chemical studies of 2amino-4-methyl-thiazole as corrosion inhibitor for mild steel in $\mathrm{HCl}$ solution. Corros. Sci. 2014; 83:310316.

13. American Society for Testing and Materials. Standard practice for preparing, cleaning,and evaluating corrosion test 2013. http://www.cosasco.com/documents/ASTM_G1_Stan dard_Practice.pdf. Accessed 11, Mar 2013.

14. Jamil DM, Al-Okbi AK, Al-Baghdadi S, Al-Amiery A, Kadhim A, Gaaz T. Kadhum A, Mohamad A. Experimental and theoretical studies of Schiff bases as corrosion inhibitors. Chem. Cent. J. ,2018; 12(7): $1-9$.

15. Al-Baghdadi S, Hashim F, Salam A, Abed T, Gaaz T, Al-Amiery A. Synthesis and corrosion inhibition application of NATN on mild steel surface in acidic media complemented with DFT studies. Results Phys 2018;8:1178-84.

16. Kadhim A, Al-Okbi AK, Jamil DM, Qussay A, AlAmiery AA, Gaaz TS. Experimental and theoretical studies of benzoxazines corrosion inhibitors. Results Phys. 2017;7:4013-9.

17. Al-Azawi K, Al-Baghdadi S, Mohamed A, AlAmiery A, Abed T, Mohammed S, Kadhum A, Mohamad A. Synthesis, inhibition effects and quantum chemical studies of a novel coumarin derivative on the corrosion of mild steel in a hydrochloric acid solution. Chem Cent J. 2016;10(1):1-23.

18. Al-Amiery AA, Kassim FAB, Kadhum AAH, Mohamad AB. Synthesis and characterization of a novel eco-friendly corrosion inhibition for mild steel in $1 \mathrm{M}$ hydrochloric acid. Sci Rep. 2016;6:4013-9.

19. Khalida F. A, Iman M M, Al-Baghdadi S B., Taghried A S, Hamsa A. I, Al-Amieryd AA, Tayser SG, Abdul Amir HK. Experimental and quantum chemical simulations on the corrosion inhibition of mild steel by 3-((5-(3,5-dinitrophenyl)-1,3,4- thiadiazol-2-yl)imino)indolin-2-one. Results in Physics. 2018;9: 278-283

20. Al-Azawi K. Synthesis, Characterization and Antioxidant Studies of Quinazolin Derivatives. Orien. J Chem. 2016; 32 (1): 585-590.

21. Taghried AS, Al.Azawi KF, Shaymaa SH. AlHashimi HR, Al-Baghdadi SB. Comparison and Evaluation studies for corrosion inhibition of mild steel in hydrochloric acid Solution by some thiadiazole derivatives. Wulfenia .2016; 23 (5) : 4658.

22. Tong ZZ, Xue JQ, Wang RY, Huang J, Xu JT, Fan Z.-Q. Hierarchical self-assembly, photo-responsive phase behavior and variable tensile property of azobenzene-containing ABA triblock copolymers. Rsc Advances.2015; 5: 4030-4040.

23. Deng Q, Shi HW, Ding NN, Chen BQ, He XP, Liu G, Tang Y, Long YT, Chen GR. Novel triazolylbisamino acidderivatives readily synthesized via click chemistry as potentialcorrosion inhibitors for mild steel in HCl. Corros Sci . 2012; 57:220-227.

24. Tao Z, Hea W, Wang S, Zhang S, Zhou G. A study of differential polarization curves and thermodynamic properties for mild steel in acidic solution with nitrophenyltriazole derivative. Corros. Sci. 2012; 60:205-213.

25. Tong ZZ, Xue JQ, Wang RY, Huang J, Xu JT, Fan ZQ. Hierarchical self-assembly, photo-responsive phase behavior and variable tensile property of azobenzene-containing ABC triblock, Copolymer j. $2015 ; 5: 4030-40$.

26. Sasikumar Y, Adekunte. Experimental, quantum chemical and Mont Carlo simulation studies on the corresion inhibtion of some alkyl imidazole ionic liquids containing tetrafluoroborate anion on mild steel in acidicmediun J .Mol Liq 2015 ;211:105-18.

27. Amin MA, Ahmed M, Arida H, Arslan T, Saracoglu M, Kandemirli F. Monitoring corrosion and corrosion control of iron in $\mathrm{HCl}$ by non-ionic surfactants of the TRITON-X series-Part II. Temperature effect, activation energies and thermodynamics of adsorption. Corros. Sci. 2011; 53: 540-548.

28. Obi-Egbedi N, Obot I, El-Khaiary M, Umoren S, Ebenso E. Computational simulation and statistical analysis on the relationship between corrosion inhibition efficiency and molecular structure of some phenanthroline derivatives on mild steel surface. Int. J. Electrochem. Sci. 2011; 6: 5649-567.

29. Nan L,Xu D,Gu T,Song X,Yang K. Microbiological influenced corrosion resistance characterisitics of a304L-Cu stainless steel against Escherichia coil. Mater Sci Eng.C 2015 ;48:228-34.

30. Verma C, Olasunkanmi LO, Obot I, Ebenso EE, Quraishi M. 2,4-Diamino-5-(phenylthio)-5 Hchromeno [2, 3-b] pyridine-3-carbonitriles as green and effective corrosion inhibitors: gravimetric, electrochemical, surface morphology and theoretical studies. RSC Advances. 2016 ; 6: 53933-53948.

31. Yadav M, Kumar S, Kumari N, Bahadur I, Ebenso EE. Experimental and theoretical studies on corrosion inhibition effect of synthesized benzothiazole derivatives on mild steel in $15 \% \mathrm{HCl}$ solution. Int. J. Electrochem. Sci ,2015; 10: 602-624. 
32. Verma CB, Quraishi M, Singh A. 2-Aminobenzene-1, 3-dicarbonitriles as green corrosion inhibitor for mild steel in $1 \mathrm{M} \mathrm{HCl}$ : Electrochemical, thermodynamic, surface and quantum chemical investigation. J. Tai. Insti. Chem. Eng. 2015; 49:229-239,.
33. Udhayakala P. Density functional theory calculations on corrosion inhibitory action of five azlactones on mild steel. J. Chem. Pharm. Res., 2014 ; 6: 117-127.

\section{دراسات كيميائية كمية وعملية لتثبيط تأكل الفولاذ الطري بواسطة 2-(ثايوفين -2- يل مثيلين) أمينو) بنزين ثايول}

| ايمان مهذي محمد حسن

قسم الكيمياء، كلية العلوم للبنات، جامعة بغداد، بغداد، العراق

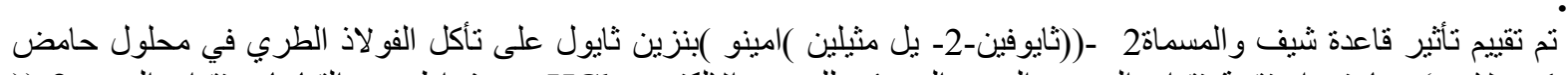

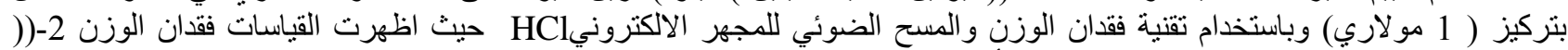

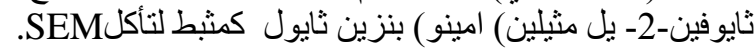

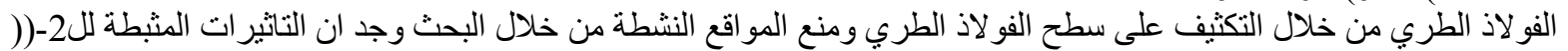

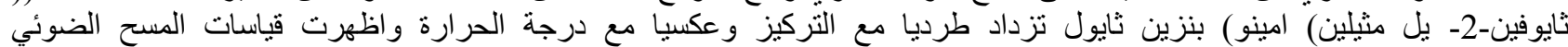

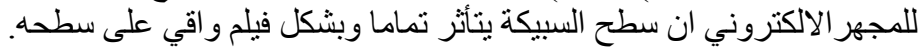

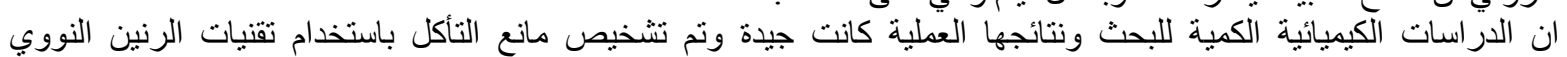

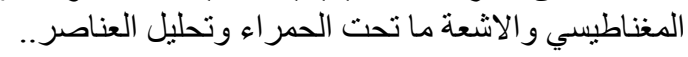
الكلمات المفتاحية: المثبط، تآكل الستيل، ثيوفين-2-كربالديهيد. 